\title{
Research on Sustainable Development Evaluation method of City Road-Network
}

\author{
Wusi Chen ${ }^{1, a}$, Xiaobo Zou ${ }^{2, b}$, Youxin Liu ${ }^{3, c}$ \\ ${ }^{1}$ Chongqing Vocational College Architectural Engineering, Chongqing 400039, China \\ ${ }^{2}$ Chongqing Vocational College Architectural Engineering, Chongqing 400039, China \\ ${ }^{3}$ Chongqing Vocational College Architectural Engineering, Chongqing 400039, China \\ a34636386@qq.com, biaobo_zou@yahoo.com, ${ }^{\mathrm{c}}$ xinran023@yahoo.com.cn
}

Keywords: Traffic engineering; sustainable development; analytic hierarchy process; city traffic

\begin{abstract}
According to the spatial distribution characteristics of the network is divided into sections and intersections of City road-network , according to the distribution of traffic flow characteristics an reference of relevant standards at home and abroad, the city traffic sustainable development degree is divided into 5 grades, selected the city sustainable development indicators, using analytic hierarchy process to establish traffic sustainable development two level evaluation index system and the corresponding fuzzy comprehensive evaluation model, and finally to a specific network traffic can develop continuously undertook determining. The research results for the assessment of city traffic sustainable development provided a kind of effective quantitative analysis method.

At present, the city traffic sustainable development quantitative description has no unified standards, mainly to saturation, speed, density or fleet retention length to judge, although these amount to a certain extent the road network traffic can develop continuously undertook certain expressions, they don't reflect the traffic sustainable development - what is the essence of the road traffic is a serious waste of resources, or imbalance of traffic order. Transport aims to make people and objects are efficient, fast, convenient moving, but regardless of is the saturation, or speed or density are not accurately, effectively describe network traffic sustainable development degree, then based on the concept of traffic congestion mitigation strategy is also not really solve the congestion problem $^{[1-6]}$. Therefore, it is important to Judge network traffic sustainable development research, it can provide traffic management departments by accurate traffic data. Appropriate to the outlet of network traffic sustainable development measures, can provide a meaningful reference, avoiding the city traffic construction expands blindly and money and waste of resources.
\end{abstract}

\section{Traffic sustainable development degree}

City traffic sustainable development degree is a reflection of traffic flow on traffic load level comprehensive evaluation index, reflect finally in sections or intersection congestion, therefore, the road and intersection traffic congestion degree were studied is on the basis of quantitative research ${ }^{[7]}$. According to the distribution of traffic flow characteristics and reference of relevant standards at home and abroad, the city traffic sustainable development degree is classified into 5 grades.

Class I: Sustainabless Development;Grade II: Weak Sustainable Development;

Grade III: common sustainable development;Class IV : Strong Sustainable Development;

Class V: The Strong Sustainable Development.

\section{City traffic congestion degree evaluation index system}

The selection of evaluation index

1) the clarity of purpose. The selected indicators should be able to clearly reflect the relevant content.

2) Scientific nature. Each index concept, symbol, formula of should be scientific, and strive to accurate. 
3) Comparability. The connotation of each index and extension should be kept stable, used to calculate each index relative value reference.

4) Overall. The selected indicators should cover all evaluation content.

\section{Index determination}

Select 6 indicators for city traffic jam judgement:

1) queue length: refers to the intersection, traffic accident point breakpoint queue holds the length of sections.

2) the two parking rate: refers to the vehicle through the intersection for two times the probability of two parking, parking rate is higher, more crowded intersection.

3) saturation: refers to the volume of traffic and road design capacity ratio, reflects the actual road load conditions.

4) running delay: due to the variety of traffic composition of mutual interference between caused delays, including longitudinal, transverse and external and internal perturbations, such as stop and wait for the crossing, traffic congestion, parking consecutive as well as pedestrians and vehicle cornering effect due to loss of time.

5) time occupancy: refers to a certain period of time, the traffic detector occupied time combined with observation time than.

6)speed: refers to the speed of vehicle average travel speed and average spot speed. The former refers to the vehicle through the specific sections of time length and the time of; the latter reflects the running status of the vehicle in a particular place.

\section{Index system}

According to the indexes of road network traffic sustainable development function, establishing the city traffic sustainable development evaluation index system of two layer.

\section{City traffic sustainable development degree evaluation model}

\section{Establishment of evaluation factors set}

The traffic sustainable development evaluation index is divided into 2 subsets $U=\left\{U_{1}, U_{2}\right\}, U_{1}, U_{2}$ Each said intersection degree of sustainable development and the sustainable development of road. As a result of road sections and intersections. Sustainable development can be respectively with different index to measure, Therefore, the subset $\mathrm{U}_{1}, \mathrm{U}_{2}$ can be divided into different level under the

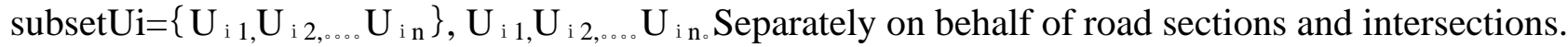
Sustainable development degrees corresponding to the two grade index, namely, queue length, two parking rates, operational delay, saturation, time share, speed and so on.

\section{Establishment of evaluation set}

The city traffic sustainable development evaluation index is divided into five class: $\mathrm{V}=$

$\{\mathrm{V} 1, \mathrm{~V} 2, \mathrm{~V} 3, \mathrm{~V} 4, \mathrm{~V} 5\}=$ S Sustainabless Development,Weak Sustainable Development, common sustainable development,Strong Sustainable Development,The Strong Sustainable Development $\}=$

\section{$\{0.9,0.8,0.7,0.6,0.3\}$}

\section{Constructing the evaluation matrix}

The evaluation index of each layer on a layer of factors important degree using the 1 9 scaling method were compared, according to expert consultation method the constraining layer on layer judgment matrix for:queue length $\mathrm{A}_{11}$ 、 two parking rates $\mathrm{A}_{12}$ 、Degree of saturation $\mathrm{A}_{13}$ 、Operational delay $\mathrm{A}_{14}$ 、 the judgment matrix $\mathrm{U} 1$ on the crossing traffic sustainable development $\mathrm{A} 1$ :

$$
\mathrm{U} 1=\left[\begin{array}{cccc}
1 & 1 / 3 & 4 & 1 / 2 \\
3 & 1 & 5 & 2 \\
1 / 4 & 1 / 5 & 1 & 1 / 3 \\
2 & 1 / 2 & 3 & 1
\end{array}\right] \quad \mathrm{2} 2=\left[\begin{array}{cccc}
1 & 1 / 4 & 1 / 2 & 1 / 5 \\
4 & 1 & 2 & 1 / 3 \\
2 & 1 / 2 & 1 & 1 / 4 \\
5 & 3 & 4 & 1
\end{array}\right] \quad \mathrm{U}=\left[\begin{array}{cc}
1 & 1 / 4 \\
4 & 1
\end{array}\right]
$$

Degree of saturation $\mathrm{A}_{13}$ 、Operational delay $\mathrm{A}_{14}$ 、Time share $\mathrm{A}_{21}$ 、 speed $_{22}$ judgment matrix $\mathrm{U} 2$ for road traffic sustainable development A2; judgment matrix $U$ for Intersection traffic sustainable 
development degreeA1、Road traffic sustainable development degrees A2 on the target layer traffic sustainable development A.

\section{To establish the weight set}

1) Calculation of judgement matrix the elements of the geometric mean $\bar{\omega}_{i}=\sqrt[n]{\prod_{j=1}^{n} a_{i j}}$, The received vector $\left[\varpi_{1}, \varpi_{2}, \varpi_{n}\right]^{T}$,For a matrix U: $\varpi_{1}=0.9036, \varpi_{2}=2.3403, \varpi_{3}=.3593, \varpi_{4}=.3161$

2) The $\omega$ standardization: $\varpi_{i}=\varpi_{i} / \sum_{j=1}^{n} \varpi_{j}, \omega=\left\lfloor\omega_{1}, \omega_{, 2}, \cdots \omega_{n}\right\rfloor^{T}$ for the feature vector. For a matrix U1: $\omega_{1}=0.184, \omega_{2}=0.478, \omega_{3}=0.073, \omega_{4}=0.268$

Ownership heavy set A1 $=\left[\begin{array}{llll}0.184 & 0.456 & 0.073 & 0.268\end{array}\right]$

3) $\lambda_{\max }=\sum_{i=1}^{n} \frac{(A w)_{i}}{n w_{i}}$, For a matrix $\mathrm{U} 1: \mathrm{U} 1 \mathrm{w}=\left[\begin{array}{cccc}1 & 1 / 3 & 4 & 1 / 2 \\ 3 & 1 & 5 & 2 \\ 1 / 4 & 1 / 5 & 1 & 1 / 3 \\ 2 & 1 / 2 & 3 & 1\end{array}\right] \times\left[\begin{array}{c}0.184 \\ 0.456 \\ 0.073 \\ 0.268\end{array}\right]=\left[\begin{array}{c}0.768 \\ 1.927 \\ 0.303 \\ 1.092\end{array}\right]$

$\lambda_{\max }=\frac{1}{4} \times \frac{0.7680}{0.1837}+\frac{1.9268}{0.4757}+\frac{0.3032}{0.0730}+\frac{1.0918}{0.2675}=4.1165$

4) Consistency criterion

$\mathrm{CI}=\frac{\lambda_{\max }-n}{n-1}=\frac{4.1165-4}{3}=0.0388 \quad \mathrm{CR}=\frac{C I}{R I}=0.0436<0.1$, The consistency of the judgment matrix is acceptable. Similarly, the matrix $U 2$, $U$ set of weights respectively:
$\mathrm{A} 2=[0.0652,0.3628,0.1159,0.4562]$
$A=[0.2,0.8]$

\section{Evaluation model}

On second factors set the single factor evaluation. Design factors on the evaluation set element's membership, then

$$
\left.\bar{R}=\left[\begin{array}{ccccc}
r_{i 11} & r_{i 12} & r_{i 13} & r_{i 14} & r_{i 15} \\
r_{i 21} & r_{i 22} & r_{i 23} & r_{i 24} & r_{i 25} \\
\cdots & \cdots & \cdots & \cdots & \cdots \\
r_{i p 1} & r_{i p 2} & r_{i p 3} & r_{i p 4} & r_{i p 5}
\end{array}\right]\right)
$$

According to the type of ( 1 ) type (3) computing level fuzzy comprehensive evaluation matrix

A fuzzy comprehensive evaluation of the $U$ reaction as a factor to judge object effect, get the judgment matrix of two stage fuzzy comprehensive evaluation of single factor evaluation matrix. On the basis of this type (4 ) of all of the factors were judged, two level fuzzy comprehensive evaluation set:

$$
\bar{B}=\theta \cdot \bar{A}=\left(\theta_{1}, \quad \theta_{2}, \theta_{3}, \theta_{4}\right) \times\left[\begin{array}{ccccc}
a_{11} & a_{12} & a_{13} & a_{14} & a_{15} \\
a_{2} & a_{22} & a_{23} & a_{24} & a_{25} \\
a_{31} & a_{32} & a_{33} & a_{34} & a_{35} \\
a_{41} & a_{42} & a_{43} & a_{44} & a_{45}
\end{array}\right]=\left\{\mathrm{b}_{1}, \mathrm{~b}_{2}, \mathrm{~b}_{3}, \mathrm{~b} 4, \quad\right\}
$$

\section{Numerical example}

A network of 5 intersection, 6 sections, two O-D $(1,5)$ and $(2,5)$. The node from the node to the destination node. The, the vehicle can respectively select 1-3-6, 1-4-6, 1-5-6 and 2-3-6, 2-4-6, 2-5-6 3 path. Network parameters respectively as shown in Table 1, table 2.

Table 1 the test road sections of main parameters

\begin{tabular}{|c|c|c|c|c|c|c|c|}
\hline num & $\begin{array}{c}\text { The } \\
\text { number of } \\
\text { lanes } /\end{array}$ & $\begin{array}{c}\text { Length } \\
/ \mathrm{km}\end{array}$ & Capacity $/\left(. \mathrm{h}^{-1}\right)$ & Traffic. $\left(. \mathrm{h}^{-1}\right)$ & speed $\left(\mathrm{km} \cdot \mathrm{h}^{-1}\right)$ & $\begin{array}{c}\text { Degree of } \\
\text { saturation } / \\
\left(\mathrm{C}^{-1}\right)\end{array}$ & Share $/ \%$ \\
delay/s
\end{tabular}




\begin{tabular}{|c|c|c|c|c|c|c|c|c|}
\hline & article & & & & & & & \\
\hline 1 & 4 & 1.8 & 5354 & 2357 & 34 & 0.46 & 45 & 16 \\
\hline 2 & 4 & 1.8 & 5262 & 2418 & 35 & 0.44 & 44 & 13 \\
\hline 3 & 2 & 6.3 & 1600 & 885 & 31 & 0.55 & 52 & 45 \\
\hline 4 & 4 & 5.5 & 3024 & 2720 & 10 & 0.9 & 88 & 272 \\
\hline 5 & 2 & 6.4 & 1637 & 915 & 28 & 0.56 & 54 & 62 \\
\hline 6 & 6 & 2.2 & 6100 & 4320 & 30 & 0.71 & 72 & 25 \\
\hline
\end{tabular}

Table 2 the main parameters of test road intersection

\begin{tabular}{|c|c|c|c|c|c|c|}
\hline num & Capacity / $\left(. \mathrm{h}^{-1}\right)$ & Traffic. $\left(. \mathrm{h}^{-1}\right)$ & $\begin{array}{c}\text { Degree of } \\
\text { saturation } /\left(\mathrm{C}^{-1}\right)\end{array}$ & $\begin{array}{c}\text { Queue length } \\
/ \mathbf{m}\end{array}$ & $\begin{array}{c}\text { The two stop } \\
\text { rate } / \%\end{array}$ & delay /s \\
\hline 1 & 3600 & 1836 & 0.51 & 35 & 15 & 22 \\
\hline 2 & 3800 & 2356 & 0.62 & 47 & 21 & 19 \\
\hline 3 & 5200 & 3900 & 0.75 & 98 & 35 & 25 \\
\hline 4 & 6500 & 5785 & 0.89 & 125 & 65 & 52 \\
\hline
\end{tabular}

According to various road sections and intersections. Important degree, using analytic hierarchy process and expert scoring method comprehensive evaluation, each section and intersection traffic condition on the whole traffic sustainable development status of weight as shown in table 3 .

\section{The single factor evaluation}

The intersection of each factor weight coefficient WD on A11, A12, A13 index, A14, evaluation set of single factor evaluation matrix for:

The intersection of the evaluation (1)set as:

$\mathrm{C}_{11}=\mathrm{W}_{\mathrm{D} 1} \cdot \mathrm{R}_{11}=(0,0.14,0.39,0.47,0)$

Similarly, intersection(2) - (5)、 (1)_(6)the evaluation set as:

$\mathrm{C} 12=(0,0.175,0.393,0.433,0) \mathrm{C} 13=(0.18,0.375,0.325,0.12,0)$
$\mathrm{C} 14=(0.43,0.55,0.02,0,0)$
$\mathrm{C} 15=(0.4,0.465,0.355,0.14,0)$
$\mathrm{C} 21=(0,0.11,0.335,0.485,0.07)$
$\mathrm{C} 22=(0,0.07,0.293,0.493,0.145)$
$\mathrm{C} 23=(0,0.08,0.365,0.465,0.025)$
$\mathrm{C} 24=(0.545,0.425,0.03,0,0)$
$\mathrm{C} 25=(0,0.13,0.445,0.39,0.035)$
$\mathrm{C} 26=(0,0.455,0.325,0.19,0.03)$

\section{Level fuzzy comprehensive evaluation}

The intersection traffic parameter level fuzzy comprehensive evaluation model, get all the intersections of level fuzzy comprehensive judgment:

$\mathrm{C} 1=\mathrm{WC} 1 \cdot \mathrm{R} 1=(0.74,0.417,0.233,0.131,0)$

Similarly, all sections of a class of fuzzy comprehensive evaluation for:

C2=WC2 $\cdot$ R2 $=(0.164,0.338,0.242,0.217,0.037)$

\section{Two fuzzy comprehensive evaluation}

The C1, C2 as single factor evaluation matrix, get the whole traffic jam of two level fuzzy comprehensive evaluation for: $\mathrm{C}=\mathrm{W} \cdot \mathrm{R}=(0.222,0.34,0.191,0.109,0.001)$,According to the principle of maximum degree of membership, get the intersection of the sections of the (1) - (5) 、(1)_(6), all intersections, all sections, the entire road network traffic congestion degree of membership are:strong-sustainable-development;sustainable-development,weak-sustainable-development, weaksustainable-development, weak-sustainable-development,sustainable-development;strong-sustainabl e-development,sustainable-development,sustainable-development,weak-sustainable-development; $w$ eak-sustainable-development;sustainable-development;weak-sustainable development.

\section{Conclusions}

The city traffic sustainable development is divided into 5 grades, selects network traffic sustainable development evaluation index, established the city traffic sustainable development evaluation index system and the corresponding fuzzy comprehensive evaluation model, and the testing road network traffic sustainable development status of evaluation. The results of numerical examples show that using the method of city traffic sustainable development of the judgment is feasible and effective.

\section{Reference}


[1] Southeast University Transportation History Research Institute, the sustainable development of city traffic system ( key project of National Natural Science Fund project report, 1998 ) .

[2] Wang Wei, a TranStar ( delivery of Star City Edition ), Transportation College of Southeast University, 2001.6

[3] Wang Wei, Xu Jiqian, Yang Tao, Li Xuhong, " city transportation planning theory and Its Applications ", Nanjing, Southeast University press, 1998.9

[4] Li Xuhong, " road traffic planning ", Nanjing, Southeast University press, 1997 [5] Zhou Ganzhi, " development of traffic of our country big city research ", China Building Industry Press, 1997

[6] Li Xiaojiang, " Chinese city transportation development strategy ", China Building Industry Press, 1997

[7] Measurement of the valuation of travel time savings, David A.Hensher, Journal of transport ecomomics and policy,Volume3 5,Part1,2001.1 